\title{
The battle between fake news and science
}

L. Harper a, *, K.W. Herbst b, D. Bagli c, M. Kaefer d, G.M.A. Beckers e, M. Fossum f,g, N. Kalfa h, On behalf of the ESPU research committee

A Service de Chirurgie

Pediatrique, Hospital Pellegrin-Enfants, CHU de Bordeaux, France

B Division of Urology, Department of Research, Connecticut Children's Medical Center, Hartford, CT, United States

C Division of Urology, Departments of Surgery and Physiology, University of Toronto, Developmental and Stem Cell Biology, The Hospital for Sick Children and Research Institute, Toronto, Ontario, Canada

D Riley Hospital for Children, Indiana University, Indianapolis, IN, United States

E Department of Urology, Pediatric Urology Section, Amsterdam University Medical Centre Location VUmc, Amsterdam, the Netherlands

F Department of Pediatric Surgery, Surgical Clinic C, Copenhagen University Hospital, Rigshospitalet, Denmark

G Department of Women's and Children's Health, Karolinska Institutet, Stockholm, Sweden

H Service de Chirurgie et Urologie Pe'diatrique, Ho^pital Lapeyronie, CHU de Montpellier, Universite’ de Montpellier, France

Fake news is fabricated information that mimics news media content yet lacks the editorial norms and processes that ensure accuracy and credibility [1]. This includes misinformation (misleading information) and disinformation (false information purposely spread to deceive people).

Fake news in science and health translates into health-related claims that lack scientific evidence or are simply untrue. They are abundant on social media, and the adverse effects of exposure to fake news on health behaviors and outcomes have been shown [2,3]. There is, however, scarce information on how

This is the author's manuscript of the work published in final edited form as:

Harper, L., Herbst, K. W., Bagli, D., Kaefer, M., Beckers, G. M. A., Fossum, M., Kalfa, N., \& ESPU research committee. (2020). The battle between fake news and science. Journal of Pediatric Urology, 16(1), 114115. https://doi.org/10.1016/j.jpurol.2019.12.004 
to react to false beliefs [4]. Understanding how and why fake news spreads is the first step in finding a response to this curse.

Several factors have facilitated the rise of fake news. In the past, only a handful of organizations could afford to communicate, and their biases were well known. Information was available through a few newspapers, radio, or television channels. But now, with social media, anybody can become a news outlet simply with a tweet or post [5]. Similarly, there is an increasing ability to select information sources, and because of the detrimental allure for immediacy, social media is gaining popularity as a pseudomedia outlet. Furthermore, misinformation has no constraints and can be specifically designed to spread. In a recent study on the differential diffusion of all true and false news stories on Twitter 20062017, which included 126,000 cascades of news stories, the authors found that falsehood, especially about politics, urban legends, and science, was $70 \%$ more likely to be retweeted than the truth [6]. Contrary to popular belief, internet bots (i.e., software applications that run automated tasks) accelerated the spread of both true and false news at the same rate, implying that it is truly humans that are responsible for the spread of false news.

So why does fake news spread? We crave information. We crave novelty. We confer more value to information (information entropy), depending on how surprising it is, because we need new information to continuously update our understanding of the world (Bayesian decision theory). We thrive on novelty because it provides the greatest aid to decision-making and because it conveys the social status of being 'in the know.' It is, simply said, more valuable. And false news is perceived as more novel than true news.

There is also cognitive dissonance and bias. Cognitive dissonance is the mental discomfort generated by holding contradictory beliefs. People prefer information that confirms their pre-existing attitudes and 
view such information as more persuasive than dissonant information (confirmation bias). They more easily accept information that pleases them (desirability bias).

What can we do? Science should not be a popularity contest. Aggregators that collate records of online activity, regardless of the scientific value of this activity, might be sending the wrong message. We need to rehabilitate the notion of reliable source, credit information from recognized scientific journals, and discredit unreliable information. Accepting unproven facts has helped discredit traditional medicine.

We must, and can, reinforce the peer review process, which is structurally designed to separate fact from fiction, and beware of preprint publication and open access. If we engage on social media, we must do so thoughtfully and understand how information is perceived.

We must fight back.

\section{Author statements}

\section{Funding}

None declared.

\section{Competing interests}

None declared. 


\section{References}

1. Lazer D.M.J., Baum M.A., Benkler Y., Berinsky A.J., Greenhill K.M., Menczer F., et. al.: The science of fake news. Science 2018 Mar 9; 359: pp. 1094-1096.

2. Johnson S.B., Park H.S., Gross C.P., Yu J.B.: Complementary medicine, refusal of conventional cancer therapy, and survival among patients with curable cancers. JAMA Oncol 2018; 4: pp. 13751381.

3. Sharma M., Yadav K., Yadav N., Ferdinand K.C.: Zika virus pandemic-analysis of Facebook as a social media health information platform. Am J Infect Contr 2017; 45: pp. 301-330.

4. Merchant R.M., Asch D.A.: Protecting the value of medicalscience in the age of social media and "fake news". J Am Med Assoc 2018 Dec 18; 320: pp. 2415-2416.

5. Chou W.S., Oh A., Klein W.M.P.: Addressing health-related misinformation on social media. J Am Med Assoc 2018 Dec 18; 320: pp. 2417-2418.

6. Vosoughi S., Roy D., Aral S.: The spread of true and false news online. Science 2018 Mar 9; 359: pp. 1146-1151. 